\title{
Elaboración bíblico-teológica de Ronaldo Muñoz
}

\author{
Diego Irarrázaval \\ UNIVERSIDAD CATÓLICA SILVA HENRÍQUEZ
}

El conocimiento tiene -en muchos ámbitos- un carácter espectacular: un individuo da explicaciones y cautiva a sus consumidores. Esto a veces ocurre en espacios sagrados. Sin embargo, existen otras vías. A mi parecer, un buen camino es la elaboración y recepción en comunidad, que alienta y empodera a diversas personas.

Desde los años 60 y hasta su pascua el 2009, Ronaldo Muñoz ha contribuido al carisma teológico del pueblo de Dios. Ha conjugado la reflexión sistemática, bíblica, testimonial. Lo hizo en acontecimientos eclesiales y ámbitos académicos, en comunidades cristianas en sectores populares, en proyectos sociales y en eventos públicos. Todo esto constituye una hazaña teórica-práctica. En el contexto chileno uno pregunta ¿quiénes siguen sus pasos innovadores e interpelantes? ¿Nos acomodamos?

El seminario interno (en la Facultad de Teología de la PUC) ha ingresado en un tercer momento, dedicado a contextos biográficos, y a textos de K. Rahner y de R. Muñoz, y de la teología feminista. La sesión de hoy tiene como marco lo elaborado en rincones del continente y de nuestro país. Es un arduo y bello itinerario desde los años 60 hasta la primera década de este siglo. No voy a recapitular y evaluar fases y corrientes de la teología latinoamericana, ni provechosas controversias, ni la serie de censuras y malentendidos, ni la polifónica e incesante creatividad. Más bien junto con ustedes deseo acercarme a un buen manantial, a un entrañable maestro.

Hace poco un colega me sorprendió al decir: Ronaldo ha hecho poca teología. Esta opinión muestra un prejuicio, o bien indica la preferencia por otro modo de pensar. La obra de R. Muñoz, y la coherencia entre lo 
vivido y lo escrito, ha sido monumental ${ }^{1}$. Voy a comentar su elaboración bíblica-teológica en comunidad ${ }^{2}$. Ojalá en otra ocasión sean minuciosamente examinados modos como este autor (y como otros biblistas chilenos) redimensionan la reflexión, al hacerla en comunidad.

$\mathrm{Su}$ intenso y muy apreciado testimonio como creyente no es materia de este ensayo. Más bien comento su infatigable modo de compartir bíblico-teológico, que es una buenísima veta que ojalá siga siendo traba-

1 Véanse los libros publicados por Ronaldo Muñoz: La tolerancia cristiana en el mundo de hoy (Santiago 1964); Nueva conciencia de la Iglesia en América Latina (Santiago 1973, Salamanca 1974, Petrópolis 1979); Evangelio y Liberación en América Latina: la teología pastoral de Puebla (Santiago 1980, Bogotá 1980); La Iglesia en el pueblo. Hacia una eclesiología latinoamericana (Lima 1983, Petrópolis 1985); Dios de los cristianos Santiago 1988, Madrid 1988, Petrópolis 1988); Llamados desde el pueblo (Santiago 1990); Pueblo, comunidad, evangelio: escritos eclesiológicos III (Santiago 1994); Pobres, Evangelio, Poder. Versos libres (Santiago 1998); La Trinidad de Dios Amor ofrecido en Jesús el Cristo (Santiago 2000); Ser Iglesia de Jesús en poblaciones y campos. Eclesiología de Base (Santiago 2002); Quién es Jesús; de qué manera es Cristo, y qué significa hoy ser sus discípulos y misioneros (Santiago 2006); Nueva conciencia cristiana en un mundo globalizado (Santiago 2009). No consigno innumerables artículos en revistas latinoamericanas y europeas, aportes en varias publicaciones de la Vicaría de Solidaridad en Chile, sus 12 años como director de la revista Pastoral Popular, varias entrevistas, mucha teología narrativa en toda clase de encuentros, sínodos, congresos, talleres. (Muchos manuscritos, cartas a instancias de Iglesia, y esquemas de cursos dados por R. Muñoz, se encuentran en el Archivo Provincial de los Sagrados Corazones en Santiago.)

2 Cada persona es indefinible; pero ciertos rasgos llaman la atención. En la sistemática y cálida trayectoria de R. Muñoz sobresale la teología-en-comunidad. Ha sido asesor en programas locales y continentales de la Iglesia y en la renovación de la vida religiosa, poblador marginal, colaborador en los derechos humanos, presbítero (de los Sagrados Corazones), editor de una revista. ¡También ha sido ascético y gozador, muy atento a cada persona, constructor de relaciones, inconformista en la sociedad y en la Iglesia, soñador! En Chile y otras latitudes, junto a Ronaldo Muñoz (1933-2009) resaltan los itinerarios bíblico-teológicos de Fernando Castillo (1943-1997) con su erudición vinculada al movimiento social, Bernardo Hurault (1924-2004) con la gestación comunitaria de la Biblia Latinoamericana, Segundo Galilea (1998-2010) con su teología espiritual, José Comblin (1923-2011) con su reflexión pluridimensional. Son amigos que descansan en el Reino. Con diversas enfoques han contribuido a la reflexión bíblico-teológica: Roberto Bolton y la amplia corriente de lectura popular, grandes maestros: Beltrán Villegas, Antonio Moreno, Jaime Moreno, Pablo Richard, Miguel Ángel Ferrando, Sergio Silva, y las nuevas generaciones: Eduardo Pérez Cotapos, Sergio Armstrong, Arturo Bravo, Pablo Uribe, César Carbullanca, Andrés Ferrada, Ignacio Chuecas, Ricardo Cortés, Fernando Ramos, Rebeca Guzmán, Javier Cortés, Rosa Estela Yáñez, Katiuska Cáceres. 
jada en diversos espacios eclesiales. La hermenéutica llevada a cabo por R. Muñoz constituye una hazaña desde la marginalidad.

Voy a comentar cuatro rasgos: a- coraje en el modo de pensar, b- luces y sombras en las guías de lectura bíblica, c- correlación entre realidades humanas y la Revelación, d- dificultades y cuestiones abiertas que tienen -a mi parecer- mayor relevancia. Son cuatro rasgos que desinstalan, que confrontan mediocridades, que convocan a trabajos de largo aliento.

\section{1) Valentía metodológica}

El sentido común no propicia el culto a personas ni absolutiza las actividades intelectuales. Ello sería aún más inaceptable en los ambientes críticos de la reflexión latinoamericana. Por otra parte, personas cercanas a Ronaldo constatábamos sus limitaciones. Además, su genuina humildad no permite ponerlo sobre un pedestal.

Sin embargo, hay consenso sobre su lucidez evangélica, y su labor sistemática en organismos pastorales y junto a comunidades de base. R. Muñoz ha dialogado con diversos sectores sociales, y ha empleado varios lenguajes y metodologías. No ha estado delimitado por una sola institución académica, ni ha sido especialista en Biblia. Más bien ha escuchado la Palabra en el caminar del pueblo de Dios en América Latina. Esto sobresale en Nueva Conciencia de la Iglesia, y en Ser Iglesia de Jesús. Su labor teológica es innovadora en lo sistemático -en especial en el Dios de los Cristianos-, en versos libres -como en Pobres, Evangelio, Poder-, en sus guías de Lectura Bíblica -como en Quién es Jesús...-, y en una gama de cartas, homilías, ensayos -como en Pobres, Evangelio, Poder-. Esta vasta y multiforme producción ¿puede ser vista como precursora de la hoy llamada teología práctica? Creo que sí.

En medio de la actividad evangelizadora y de varios tipos de producción escrita, una constante ha sido el coraje del maestro Muñoz, al entender y al comunicar fielmente la Palabra. Esto conllevó confrontar el pasado reciente, ya que «no había una interacción directa con la palabra de Dios, la que quedaba oculta detrás de la doctrina, llámese catecismo o manuales de teología ${ }^{3}$. Con tenacidad y con coraje se ha desenvuelto su obra polifacética. Ella fue cultivada en Los Perales (ver su La tole-

3 C. Venegas - E. Moreno, Conversaciones con Ronaldo Muñoz (Santiago 2010), 73. Otro pasaje: colocar «la Biblia en manos de los pobres» es uno de los mayores cam- 
rancia cristiana...), en sus estudios en Roma, Paris, Regensburg, en su reflexión en Río Bueno, y en sus largos años en poblaciones marginadas, como por ejemplo en la zona sur «con diez vecinos y vecinas... desde los márgenes de la sociedad y las fronteras de la iglesia» ${ }^{4}$. Detengámonos en esto.

Ha reflexionado con genuina libertad y valentía, tanto en ámbitos de privilegio como en los márgenes de estructuras sociales y eclesiales. No ha enseñado a fin de ganar estatus. Ha sido un disidente ante saberes hegemónicos (y esto ha implicado la exclusión de la Facultad de Teología). Como maestro ha vuelto su mirada a las raíces; se ha desapegado de esquemas convencionales. Abrió sus ojos y oídos a otra Biblia y otro Jesús. De modo apasionado ha comunicado lo que iba aprendiendo de comunidades de base que escuchaban al Espíritu de Jesús y que eran solidarias con el pobre. Recalco esto: gracias a su libertad evangélica y su valentía teológica puede redescubrir la Biblia y al Señor Jesús.

En la población Malaquías Concha, en la comunidad María de la Esperanza, «empezaba a descubrir otra Biblia, otro Jesús, la experiencia fuerte de la hermandad cristiana, de la solidaridad en medio del pueblo... la lectura de la Biblia con los pies en la tierra, con los ojos bien abiertos, se integraba a un pensamiento teológico más elaborado y técnico en vista de la docencia y asesoría teológica que se me iba pidiendo, ya fuera en la ciudad, en el país o en América Latina».

El contacto con la Palabra encarnada en comunidades es conjugado con la docencia en que dialoga con las personas y en la investigación que retoma lo pensado en muchas latitudes. De este modo la labor teológica sintoniza con la sabiduría y ciencia que el Espíritu regala a la comunidad cristiana para el provecho común (1 Cor 12:7-8). Esto conlleva una audacia creativa, una neotestamentaria parresia. Esto implica una interpelante metodología ${ }^{6}$.

bios en nuestra iglesia latinoamericana (C. Venegas - E. Moreno, Conversaciones con Ronaldo Muñoz, 92).

4 Quién es Jesús, 53.

5 R. Muñoz, citado por Venegas y Moreno, 186-187.

6 En el Seminario del 27/9/2011, luego de la ponencia, hubo varios aportes. Fredy Parra explicó el método de inserción teológica. Cristina Bustamante comentó el pensar en situación ante la injusticia, y la pertenencia (siguiendo a Gadamer). Joaquín Silva subrayó la hermenéutica desde la marginalidad, redescubrir nuestra 


\section{2) LUZ Y SOMBRA EN LAS GUÍAS BÍBLICAS COMUNITARIAS}

Numerosos talleres y cursos fueron llevados a cabo por R. Muñoz en comunidades ${ }^{7}$. Para ello pacientemente ha elaborado guías que reiteradamente corregía y ampliaba ${ }^{8}$. Son lúcidos textos, con un carácter programático, y son frutos de una labor bíblica compartida. En esos escritos uno constata las líneas gruesas trazadas por el asesor, y los contenidos asimilados por varias comunidades. A esto último se debe la sencilla profundidad de los textos (diferentes a los que uno encuentra en la literatura especializada). El objetivo de toda esta labor puede resumirse así: un reflexivo encuentro con la humanidad del Resucitado. También puede ser descrito como un aporte jesucristológico ${ }^{9}$, en que la comunidad alimentada por la Palabra es convocada al discipulado.

Las Guías Bíblicas ofrecen: a- selección de textos (mayormente del Nuevo Testamento), b- subtítulos y estrofas que son leídas por los/las participantes, y c- comentarios y resúmenes, ya sea de conocimientos adquiridos en el taller o bien de aclaraciones dadas por el asesor. La estructura y también los contenidos están claramente orientados al contacto sapiencial con el Señor (y no a un erudito juego con referencias

historia con Dios, ser comunidad, y la autocomunicación de Dios. Geraldo de Mori (S.J. de Belo Horizonte) señaló lo hermenéutico como un arte de comunicación entre el mundo popular y el académico; lo teológico como dar testimonio del Evangelio; y la existencia de distintas epistemologías.

7 En sus escritos, R. Muñoz agradece a comunidades en Santiago y sus alrededores: Quilpué, Los Perales, João Goulart, Malaquías Concha, Yungay, Lo Espejo; y a poblados en el sur y en Argentina: Río Bueno, Los Lagos, Lago Ranco, Neuquén, Moreno, barrios de Buenos Aires.

8 Véanse las principales compilaciones de pautas de lectura comunitaria en: Ser Iglesia de Jesús en poblaciones y campos. Eclesiología de Base, 32-60, con 7 fichas bíblicas; Quién es Jesús; de qué manera es Cristo, y qué significa hoy ser sus discipulos y misioneros, 11-63 (un cuaderno de lectura bíblica, con 9 fichas, y con tres presentaciones sintéticas de talleres). Seis fichas "teo-prácticas» para la lectura orante del NT son incluidas en una conmemoración de los 35 años de Medellín (en Nueva Conciencia Cristiana en un mundo globalizado, 246-7; elementos ya publicados el 2006, en Quién es Jesús..., 62-63). Hubo 4 guías de lectura bíblica en su libro de los años 80 (Dios de los cristianos), 217-223. (Véanse otros manuscritos y esquemas en el Archivo Provincial de la Congregación de los Sagrados Corazones.)

9 La renovada teología latinoamericana ha entendido al Hijo de Dios desde su humanidad (y por eso esta anclada en los relatos evangélicos) y ha puesto acento en el discipulado. Ofrece pues una jesucristología vivencial. 
bíblicas). A continuación anotaré en general lo luminoso (en el sentido de aciertos) y lo sombrío (en el sentido de ocasiones para descansar y redimensionar el caminar bíblico).

Unas luces. Las Guías no son un enjambre de textos, sino que permiten recorrer y entender secciones neotestamentarias: Marcos del $1 \mathrm{al}$ 8, misión galilea en los sinópticos, discipulado según Mateo, peregrinar con Jesús en Lucas 9 a 19, comunidad en Hechos 1 al 15, iglesia paulina en las Cartas, secciones del cuarto Evangelio, relatos de la Cena del Señor. A fin de abrir mentes y corazones al Mensaje se emplean subtítulos y estrofas, y referencias a pasajes bíblicos que nutren la praxis creyente ${ }^{10}$. Hay algunos registros de preguntas y del diálogo comunitario, que probablemente fue lo más fecundo ${ }^{11}$.

En las Guías Bíblicas algunas secciones son versos libres (con un mínimo de palabras y un máximo de enseñanza), y otras secciones contribuyen a la profundización. Todo el material vibra con la experiencia de Dios. También es notable la fundamentación del encuentro personal y eclesial con Jesucristo. Se trata de fichas elaboradas mayormente en los años 90 y los años recientes, antes de la realización de la V Conferencia en Aparecida, que ha tenido esta línea de fondo: el encuentro con el Señor. Las Guías afianzan la fe y permiten pensarla en comunidad.

Unas sombras. En la comprensión del Mensaje, sobresalen los contenidos bíblicos de carácter grupal, e insuficiente atención es prestada al

10 Por ejemplo: «Viviendo según el Espíritu en convivencia...

(Gál 5: 13-26, Filip 2:1-11, Rom 12: 9-21, 1 Cor 10: 23-11: 1,13: 4-7).

De allí que en las comunidades cristianas

se tenga que convivir sintiendo y actuando

movidos no por "la carne", sino por el Espíritu,

conforme a los sentimientos y actitudes de Jesús:

en la hermandad cálida y alegre,

en el amor humilde y compasivo,

servicial y desinteresado,

siempre constructivo de las personas

y de la misma comunidad» (Quién es Jesús..., 36)

11 Son notables las preguntas y registros de diálogos en las Guías de Marcos y Lucas, y en la Visión Sintética en Quién es Jesús..., 14-15, 22-30, 47-57, 64-70. Ojalá la futura labor bíblica registre más diálogos comunitarios. 
proceso de individuación que caracteriza la existencia contemporánea ${ }^{12}$. Conviene encarar la tensión entre la comprensión comunal de la Palabra y los esquemas de fe privada en el mundo globalizado. Esto afecta los modos de acercarse a los textos bíblicos. Algunas guías y síntesis hechas por R. Muñoz ofrecen conexiones con el contexto actual, mediante preguntas para el discernimiento bíblico, y mediante breves párrafos de síntesis.

Sería oportuno sentarse a la sombra... y reconsiderar algunas temáticas. Cabría desenvolver más los itinerarios personales dentro de la comprensión comunitaria, los modos como el mensaje neotestamentario impugna el poder sacralizado, la difícil interacción entre distintas culturas/ religiones, el empoderamiento de la mujer y sus modos de escuchar a Dios, las dinámicas de sanación con que muchos acuden a la Biblia. Estos y otros desafíos ofrecen nuevas preguntas y modos de interiorizar el Evangelio. Algunos de estos factores son mencionados en las Guías de lectura; y requieren de un mayor desarrollo. Vale pues descansar a la sombra... y ahondar y ampliar los insumos bíblico-teológicos.

Como es bien sabido, el renovador movimiento bíblico en América Latina no es autocentrado, sino más bien se ha puesto al servicio de la Vida. Al decir de Carlos Mesters no se trata de encerrarse en textos, sino en interpretar la vida con la ayuda de la Biblia ${ }^{13}$. Esto es llevado a cabo en diversos ámbitos y de modo especial en la liturgia; así lo ha hecho Gustavo Gutiérrez en sus comentarios bíblicos en un sector de Lima ${ }^{14}$. Estas actividades no se improvisan. De modo riguroso muchas personas a la luz de la Palabra (¡y a su sombra!) se han dedicado tanto a discernir

12 Con respecto al sujeto y al «individualismo liberador», véase A. Touraine, Un nuevo paradigma (Buenos Aires 2005), 109-126, 129-179; con respecto a la individuación véase D. Martuccelli, Cambio de rumbo (Santiago 2007), 30-35, 117 134. Lo individual constituye hoy un principio transcendente, y es interpretado de varias maneras.

13 Véase C. Mesters, Uma flor sem defessa (Petrópolis 1983), Lecturas Bíblicas (Estella 1986), 21. Aquí anota: «llevar al interior de la Biblia la pregunta que la vida suscita en nosotros... y mirar con la luz de Dios la vida y los problemas que la vida suscita; esto nos ayuda a encontrar la solución, y nos da más coraje y esperanza». También, Hacer arder el corazón (Estella 2006).

14 Véase G. Gutiérrez, Compartir la Palabra, a lo largo del año litúrgico (Lima 1995). La mayor parte de estas reflexiones han sido generadas en una viceparroquia en un barrio del Rímac, Lima. 
tendencias hacia la deshumanización como las tendencias hacia una vida más plena.

Gilberto Gorgulho visualiza la hermenéutica como un «discernimiento... para penetrar más a fondo tanto en los mecanismos de muerte y de dominación como en la fuerza de la resurrección y de la vida plena del pueblo de Dios en el mundo»" ${ }^{15}$. Por lo tanto, la hermenéutica tiene sujetos y horizontes históricos, que configuran la reflexión sobre Dios, la misión eclesial, y las aspiraciones humanas a la felicidad ${ }^{16}$.

\section{3) Correlación: Realidades humanas y ReVelación divina}

Pensar lo humano junto a lo divino es casi imposible cuando se emplean parámetros dualistas y yuxtaposiciones. Por otra parte, la reflexión cotidiana ha sido segregada de la teología sistemática (y la segunda apartada de la primera). Resolver estas disyuntivas ha sido una gran preocupación de la perspectiva liberadora y de otras corrientes innovadoras. Al revisar las obras de Ronaldo Muñoz es palpable su riguroso pensar en medio (y no segregado) del Pueblo de Dios.

El «teólogo de población de marginal» (como fue calificado por $E l$ Mercurio) ha trabajado con una metodología audaz y comunitaria (reseñada en los párrafos anteriores). No solo eso. También, ha cultivado una hermenéutica de correlación, y lo ha realizado en tres grandes terrenos, o mejor dicho en tres fases complementarias ${ }^{17}$. Los terrenos cultivados han

15 G. Da Silva Gorgulho, «Hermenéutica Bíblica», en Mysterium Liberationis, Conceptos fundamentales de la teología de la liberación (Madrid 1990), I:181.

16 Durante el Seminario del 27/9/2011, Mike van Treek recalcó que la teología al servicio de la fe opta por el pobre, la víctima, el marginal e indecente. Ignacio Chuecas se refiere al Deuteronomio y en general al pobre en la Biblia; y considera a Ronaldo Muñoz un ícono en la labor hermenéutica. Rodrigo Polanco se refiere a siglos de interpretación alegórica; anota que la Biblia es esencial en la teología latinoamericana; y sugiere aclarar cuál es la teología en los escritos de R. Muñoz.

17 Cada clasificación es inadecuada. Me disculpan al clasificar los escritos de nuestro autor. Ya ha sido recalcada su actividad evangelizadora en términos de lo bíblicocomunitario. La labor de R. Muñoz se mueve en 3 fases yuxtapuestas (con sus escritos correspondientes). A- La realidad/experiencia en la Iglesia latinoamericana; aquí se desenvuelve su tesis doctoral a fines de los 60 e inicios de los 70 (Nueva conciencia de la Iglesia en América Latina), y sus ensayos a fines de los 90 e inicios del siglo XX (Ser Iglesia... eclesiología de base). B- La revelación de Dios en el caminar humano; en los años 80 escribe Dios de los Cristianos (que es la obra con mayor 
sido: a- las realidades latinoamericanas en la Iglesia, b- la revelación de Dios en la experiencia humana, c- la reflexión al servicio de la vida plena. En estas temáticas un denominador común ha sido pensar interactivamente la realidad/experiencia y el encuentro con Dios gracias al Espíritu de Jesús. Esto ofrece -a mi parecer- unas claves de interpretación.

Primera clave: ¿dónde y cómo entender la Palabra?

La obra de R. Muñoz asume los clamores humanos en realidades de injusticia y de solidaridad, y lleva a cabo los correspondientes discernimientos bíblicos. De este modo encara el «evangelio de liberación» (en su primer gran libro: Nueva Conciencia de la Iglesia) y en escritos de su tercera fase. El Evangelio es leído desde espacios de sufrimiento y de esperanza, y el discernimiento tiene lineamientos bíblicos y eucarísticos ${ }^{18}$.

El contexto moderno y posmoderno sobredimensiona lo individual. En el ámbito eclesial, la implementación de Aparecida recalca el encuentro personal con el Señor. Esto a menudo tiene un carácter intimista como ocurre, por ejemplo, en pautas de la Lectio Divina. Se está devaluando el encarar y transformar lo contingente a la luz del Evangelio; y poco se subraya el ser interactivo e intercultural. En estos contextos es notable lo hecho por R. Muñoz, que releía pasajes de los evangelios y de Hechos para «despertar la atención a la vida en torno nuestro, con

consistencia) y más adelante varios ensayos de carácter sistemático. C- La reflexión al servicio de la Vida (que caracteriza todos sus escritos). De modo especial: los versos libres de Pobres, evangelio, poder (1998), Nueva conciencia cristiana en un mundo globalizado (ensayos de 1975 al 2008) que publicó mientras avanzaba su cáncer (los capítulos III, X, XI, XIX, XX retoman temáticas de Iglesia Latinoamericana, que han marcado su primera fase).

18 Con respecto a su actitud crítica, la tesis doctoral (Nueva conciencia de la iglesia en América latina, 1973) analiza 176 documentos de 1965 a 1970 (Nueva conciencia de la iglesia en América latina, 178-181) y luego en su comentario: «fundamento bíblico del slogan de la liberación, mensaje de amor (también para los ricos), y liberación integral» (182-191). Es notorio el discernimiento bíblico de documentos con rasgos proféticos, y a la vez la crítica a textos parciales y cuestionables desde la Palabra. En su obra final: Nueva conciencia cristiana en América latina (2009), el ensayo «Solidaridad liberadora, Misión de Iglesia» habla de tres columnas: pueblo de los pobres, comunidad servidora, evangelio del Reinado de Dios. Lo fundacional es la «fe y testimonio en el Dios de Jesucristo -el del Reino- que se alimentan con la lectura de la Biblia y la celebración de la Cena del Señor» (212). Dichas columnas tiene pues bases sólidas. 
la mirada de Jesús» ${ }^{19}$; esto lo hacía ante un millar de participantes en el XVIII Seminario de Formación en Neuquén.

Por consiguiente, al escuchar y reflexionar la Palabra, cabe explicitar el dónde y el cómo, a fin de conjugar vivencias humanas con la comprensión de la revelación divina. Esto constituye una primera clave de interpretación.

Segunda clave: el mensaje bíblico encara nuestras deformaciones.

La relación entre lo humano y lo divino no se lleva a cabo en un plano formal y autocomplaciente. Más bien se trata de dinámicas interpelantes y llenas del Misterio de la Vida. En cuanto a la exigente labor bíblica, ella desarrolla la "correlación dialéctica... en un itinerario de reflexión

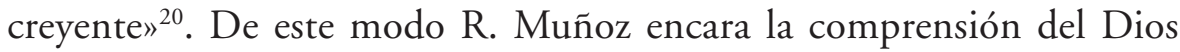
del pueblo de la alianza (empleando las categorías de Santo, Relacional, Vivo), del mensaje jesuánico (en términos del Reino, y del testimonio filial), y Dios de la comunidad (Único, Personal, Amor). La correlación se lleva a cabo entre la historia humana con Dios, y los relatos bíblicos que nos transmiten la Revelación que culmina en Jesucristo. No es pues una reflexión estática ni acrítica. Cargamos ambigüedades mentales y culturales. Por otra parte los testimonios bíblicos merecen un estudio histórico y simbólico. Todo esto presupone docilidad al Espíritu «que inspiró las Escrituras y que actúa hoy en la historia para liberación y vida de nuestros pueblos $»^{21}$.

Los escritos de R. Muñoz sobre Dios tienen como fundamento el modo como Jesús entiende al Padre. Esto permite confrontar numerosas imágenes deformadas. La sección sobre el Dios de las bienaventuranzas, del Reino, del Servidor Sufriente, de la misericordia y la vida, se refiere a problemáticas de la época neotestamentaria ${ }^{22}$. Esto motiva al lector a

19 Ver texto completo en Nueva conciencia cristiana en un mundo globalizado (2009), 219-229. Las tres grandes propuestas (reforma de la iglesia, atención a la realidad, y hacer posible "otro país») van acompañadas de una guía de lecturas bíblicas.

20 R. Muñoz, Dios de los cristianos, 69. La "correlación dialéctica entre experiencia creyente y tradición de la fe» puede revisarse en los párrafos metodológicos: 60-63, 67-70, 73-79, 161-165, 203-208; y el desarrollo de su hermenéutica en base al A. y N. Testamento en gran parte del libro: 175-256.

21 R. Muñoz, Dios de los cristianos, 74.

22 R. Muñoz, Dios de los cristianos, 214-225. 
encarar imágenes deformadas y también deidades de hoy; lo idolátrico que penetra la neocristiandad latinoamericana; las falsedades que afectan la religión popular; y de modo especial el dogmatismo del mercado. En los años 90 R. Muñoz reclamó porque la «regla de oro es: "buscad primero el reino de Mammon y su codicia, y todo lo demás vendrá por añadidura, incluso la superación de la pobreza”...»"

Tenemos pues una segunda clave de interpretación. La irrestricta fidelidad a la automanifestación divina implica confrontar absolutos contemporáneos e imágenes que deforman a Dios.

Tercera clave: la Buena Nueva en el mundo de hoy.

La Palabra es acogida «desde los pobres, a contracorriente de la dominación del consumismo individualista y excluyente» ${ }^{24}$. En la complejidad de nuestro acontecer histórico, Ronaldo Muñoz ha intervenido en la CEPAL, el parque O'Higgins, la plaza de la Constitución, la población Yungay y la Casa Azul que rehabilita a chiquillos dañados, en el IX Sínodo de Santiago ${ }^{25}$. En estas y otras ocasiones es llevada a cabo la correlación entre acontecer histórico y Evangelio de la solidaridad. Por otra parte, la elaboración latinoamericana (Ronaldo estuvo 15 años en el equipo editor de la colección Teología y Liberación) ha tenido como columna vertebral la interacción entre vivencias del pueblo y el mensaje bíblico $^{26}$. La Buena Nueva sobrepasa cada barrera (social, religiosa, con-

23 Versos en Pobres, Evangelio, Poder (1998), 38. La disyuntiva puede ser releída hoy en términos del monotheism y del moneytheism. La labor bíblica encara la actual fascinación por el mercado, y los argumentos que el crecimiento socioeconómico resuelve la pobreza.

24 Este es el largo subtítulo de su Nueva conciencia cristiana en un mundo globalizado (2009). Muchas personas hemos palpado su lucidez espiritual en la última y tan sufrida fase de su vida, cuando editaba dicha recopilación de 20 ensayos. Lo hacía en medio de difíciles acontecimientos sociales y eclesiales. Crecía su fragilidad, reflorecía su fe evangélica, y atendía a cada persona con amabilidad.

Ver J.O. Beozzo, «Colección Teología y Liberación. Un proyecto editorial interrumpido", en Amerindia, Construyendo puentes entre teologías y culturas (Bogotá 2011), 173-187. Ya que perduran malentendidos conviene anotar que la amplia perspectiva liberadora tiene vetas testimoniales, espirituales, sociopolíticas, filosófica-teológicas. Además, tiene modos de abordar el marxismo: hay mucho que «aprender del marxismo para entender mejor lo que Juan Pablo II llama los "mecanismos" de la sociedad capitalista»; unas líneas antes R. Muñoz lamentaba 
ceptual, etc.), porque el Señor se sienta en la mesa de la humanidad. Los veinte ensayos (elaborados en sus últimos 15 años) desentrañan significados de la Revelación en el caminar del pueblo de Dios.

Por lo tanto, la tercera clave de interpretación -en medio de conflictos y de esfuerzos solidarios- es desentrañar gracias a la Palabra de Vida el sentido de nuestras responsabilidades en el mundo actual.

En el conjunto de los escritos de Ronaldo, la hermenéutica bíblica es terrenal e interpelante. Ella abre los oídos al adolorido mundo que anhela transformaciones. No emplea pasajes bíblicos para respaldar anodinas generalizaciones (como suele ocurrir en la labor bíblica especializada). Más bien la transcendencia es escuchada y leída en su cercanía a la humanidad concreta. $\mathrm{Al}$ respecto existen diversos puntos de vista ${ }^{27}$.

\section{4) Dificultades y cuestiones abiertas}

La elaboración bíblica-teológica desde los márgenes ¿es capaz de moverse en diversos ámbitos y ministerios del pueblo de Dios? ¿¿Se autolimita a las comunidades de base, a ciertos movimientos laicos, a sectores hoy llamados indignados? En América Latina se constata que la hermenéutica desde abajo tiene vertientes universales. Ojalá siga siendo consolidada la frágil y exigente opción bíblica-teológica al servicio de la humanidad pobre. Este breve ensayo ha delineado la inmensidad de estos desafíos.

en sectores cristianos una "especie de beatería del marxismo como ciencia de la sociedad" (Nueva conciencia cristiana en un mundo globalizado, 145). Reconocer aciertos y límites del análisis social va de la mano con la capacidad de correlacionar el acontecer humano y la Palabra.

27 Los/las participantes en el Seminario del 27/9/2011 hemos debatido el carácter hermenéutico en la obra de R. Muñoz. Eduardo Silva comentó modos de pensar, y también la necesidad de indagar la razón teológica en el autor. En su extenso comentario Sergio Silva observaba la carencia -en la literatura teológica y pastoral latinoamericana- de rigor de método y de criticidad hermenéutica (lo que es necesario en una auténtica teologia); también subrayaba la dimensión sapiencial. Antonio Bentué mencionó el problema de ver al pobre de modo romántico; y puso acento en la misericordia de Dios con la que el pobre está más en sintonía. Ignacio Chuecas y Andrés Ferrada también comentaron el papel del pobre en la reflexión bíblica. D. Irarrázaval insistía en la existencia de diversas rutas hermenéuticas, y en la problemática de un determinado punto de vista que califica al modo de trabajar distinto como si careciera de criticidad. 
En la correlación entre realidad/experiencia y mensaje bíblico, un desafío monumental es diferenciar lenguajes, y también examinar sus entrelazamientos. A menudo la comprensión creyente es sobrepuesta al ver y actuar humano. Los aportes desde las sabidurías del pueblo y los ensayos científicos ¿se entrelazan entre ellos, y se vinculan con el discernimiento bíblico-teológico, en un proceso unitario y pluridimensional? Conviene distinguir metas y métodos del trabajo científico (por una parte) y la labor teológica (por otra parte). Esto ayuda a no caer en la sutil instrumentalización de las ciencias, y también nos incentiva a no maltratar elementos exegéticos dentro de un marco sistemático.

Existen numerosas cuestiones abiertas. Para el pueblo de Dios en Chile (afligido y desconcertado por incoherencias dentro de las estructuras cristianas) la labor bíblica tiene hoy exigencias particulares. Muchas personas claman por un pensar relevante, y enraizado en el Dios de Jesús de Nazaret. Con respecto a todo esto, estoy convencido que la obra de Ronaldo Muñoz es paradigmática, tanto en lo testimonial como en lo sistemático. ¿Continuaremos adelante con su terquedad humana y eclesial? Ello implica un pensar encarnado y universal y una amplia comunicación del Evangelio, y un desenvolver lenguajes apropiados con diversos interlocutores. Ojalá no predomine el estilo hermético empleado por las élites y por especialistas que se apropian del trabajo bíblico.

Tanto en instancias académicas como en ámbitos de la pastoral ¿con qué criterios y planes concretos es impulsada la hermenéutica desde la marginalidad? En esta primavera chilena (y disculpándome por la metáfora) Ronaldo bailaría tres pies de cueca al ver crecer la sabiduría del pueblo fiel a la Palabra.

En los organismos académicos, y de modo especial en el servicio misionero de la Iglesia, existen interrogantes abiertos. ¿La Palabra es comprendida de modo interpelante? En las instancias de formación y de investigación ¿cómo son examinadas las vetas bíblico-teológicas abiertas por Ronaldo Muñoz? ¿Cómo son retomadas las hermenéuticas de Fernando Castillo, Bernardo Hurault, Segundo Galilea, José Comblin, y otros y otras? Estas y otras elaboraciones darían mayor dinamismo a la malla curricular en cada progama académico, a eventos internos y congresos públicos, a tesis de posgrado, a programas de extensión, a la participación de exégetas y sistemáticos en la renovación de la Iglesia. 
A modo de conclusión.

En abril de 1983, Ronaldo Muñoz hacía una ingeniosa contraposición entre poco y mucho; me parece que ello puede aplicarse a cada labor bíblica-teológica. Consigno líneas de su texto:

«Pocos letrados calculadores y prudentes, muchos sencillos que saben de fe y de esperanza.

Pocos doctores muy seguros de su doctrina, muchos testigos que escuchan la verdad. Pocas ceremonias en palacios y cuarteles, muchas fiestas en aldeas y barrios marginales. Poco temor al Dios del castigo y de la muerte, mucho respeto al Dios del amor y la vida.

Poco culto, de espaldas al pueblo, a Cristo rey eterno en las alturas. Mucho amor y seguimiento a Jesús el de María, Compañero, Profeta, Hijo del Padre.

Poco, cada vez menos, mucho, cada vez más» ${ }^{28}$.

¿Podrá ser poco y cada vez menos el trabajo bíblico segregado del pobre, y podría ser mucha y cada vez más la reflexión correlacionada con la capacidad del pueblo creyente? ¿Habrá menos labor esotérica, y habrá mayor vínculo con la sabiduría de gente anónima?

Ojalá sean contagiosos los itinerarios de reflexión recorridos por Ronaldo Muñoz y otras personas que nos regalan jaudacia y terquedad!

28 R. Muñoz, «La Iglesia que amo», en Pobres, Evangelio, Poder (1998) 57. 
Resumen: R. Muñoz, «teólogo de población marginal»y religioso de los Sagrados Corazones, ha estado al servicio de comunidades cristianas en Chile, Argentina, y otras partes del mundo. Colaboró con diversos organismos eclesiales y publicó doce libros. Ha incentivado la lectura comunitaria de la Palabra que renueva a la Iglesia y transforma a la sociedad (mediante fichas bíblicas). Este ensayo recalca su audacia metodológica, luces y sombras en su material bíblico, su modo de correlacionar la Revelación y el acontecer humano, y también dificultades y cuestiones abiertas.

Palabras clave: Iglesia Latinoamericana, otra Biblia, hermenéutica desde el pobre, Revelación en la historia.

Abstract: R. Muñoz, "marginal population theologian” and religious member of the Sacred Hearts, has been serving Christian communities in Chile, Argentina and other places of the world. He worked with various ecclesial entities and published twelve books. He has encouraged the communal reading of the Word that renews the Church and transforms society (through Biblical records). This paper emphasizes his methodological courage, the lights and shadows of his biblical material, his way of correlating the Revelation and human affairs, as well as difficulties and open questions.

Keywords: Latin American Church, other Bible, hermeneutics of the poor, Revelation in history. 